TITLE:

\title{
Planetary Wave Activity in the Troposphere and Stratosphere during the Northern Hemisphere Winter
}

\author{
$\operatorname{AUTHOR}(\mathrm{S})$ :
}

Shiotani, Masato

\section{CITATION:}

Shiotani, Masato. Planetary Wave Activity in the Troposphere and Stratosphere during the Northern Hemisphere Winter. Journal of the Atmospheric Sciences 1986, 43(24): 32003209

\section{ISSUE DATE:}

1986-12-15

URL:

http://hdl.handle.net/2433/217086

RIGHT:

(C) Copyright 1986 American Meteorological Society (AMS). 


\title{
Planetary Wave Activity in the Troposphere and Stratosphere during the Northern Hemisphere Winter
}

\author{
MASATO SHIOTANI* \\ National Center for Atmospheric Research, ${ }^{* *}$ Boulder, CO 80307
}

(Manuscript received 17 February 1986, in final form 29 July 1986)

\begin{abstract}
This paper describes the correspondence of planetary wave activity between the troposphere and the stratosphere during the Northern Hemisphere winter from December 1981 to March 1982 using Eliassen-Palm (E-P) flux diagnostics. Two typical cases of correspondence are found during this period. In December and early January (period 1), the time variation of wave activity in the troposphere and stratosphere is out of phase; when the tropospheric wave activity is vigorous the stratospheric wave activity is quiet, and vice versa. In February and March (period 2), after the stratospheric sudden warming, the tropospheric wave activity seems to propagate into the stratosphere.

These two periods (period 1 and 2) are characterized by the following dynamical features. The mean zonal geostrophic wind at middle latitudes in the upper stratosphere is stronger in period 1 than in period 2 . The meridional gradient of the mean zonal wind velocity at high latitudes in the troposphere and lower stratosphere is steeper in period 1 than in period 2. Consequently, signi ficant changes in the refractive index are observed between the two periods. The E-P flux vectors in the troposphere and lower stratosphere regularly point upward in period 2, while they branch off equatorward and poleward around the tropopause level in period 1. This feature of the E-P flux pattern is in broad agreement with the refractive index.

It is also observed that there exists a strong convergence zone of the E-P flux in the upper troposphere and that the intensity of the convergence varies with a time scale of 10-15 days. This variation is closely related to that of the wave activity in the troposphere and stratosphere. Finally, it is briefly shown that some of these features for the Northern Hemisphere can be observed in the Southern Hemisphere also.
\end{abstract}

\section{Introduction}

The propagation and temporal variation of planetary waves in the atmosphere are fundamental problems in observational and theoretical studies of dynamical meteorology. These problems have been discussed for a long time and are still fascinating to many meteorologists.

In the winter stratosphere of the Northern Hemisphere, a spectacular event occurs, a so-called stratospheric sudden warming. Since Matsuno's (1971) pioneering numerical experiment on the sudden warming, it has been widely recognized that this event comes from the dynamical interaction between the mean flow and the vertically propagating planetary waves that originate in the troposphere.

Recently, because of the advantages of using satellite measurements, many observations of the sudden warming have been performed to confirm Matsuno's concept by using a powerful tool, Eliassen-Palm (EP) flux diagnostics (e.g., Palmer, 1981; O’Neill and

\footnotetext{
* Permanent affiliation: Geophysical Institute, Kyoto University, Kyoto 606, Japan.

** The National Center for Atmospheric Research is sponsored by the National Science Foundation.
}

Youngblut, 1982; Kanzawa, 1982; Gille and Lyjak, 1984; see also a suggestive review on the theoretical aspect of the sudden warming by McIntyre, 1982). The E-P flux diagnostics are particularly useful for understanding wave-mean flow interaction and planetary wave propagation. For details about the formalism and the motivation for the use of the E-P flux, the reader may refer to Edmon et al. (1980) and Dunkerton et al. (1981).

With regards to sudden warmings, there has been much discussion of why anomalous amplification of planetary waves takes place in the troposphere in connection with low-frequency variability observed in the troposphere. This atmospheric variability includes anomalous amplification related to a so-called blocking phenomenon (Wallace and Blackmon, 1983).

However, most of these studies have treated the tropospheric and stratospheric circulations as systems separate from each other. They only stressed the dynamical links between the troposphere and the stratosphere. For example, in his model study of the stratospheric sudden warming, Matsuno (1971) simply assumed the extremegrowth of planetary waves as a lower boundary condition. It is the same with studies of the low-frequency variability in the troposphere; few of them have mentioned its relation to the stratospheric circulation. 
Tung and Lindzen (1979) tried to explain the amplification of planetary waves by regarding the troposphere and stratosphere as a whole system. Using a general circulation model, Boville (1984) showed the influence of the stratospheric wind structure on the tropospheric circulation and stressed the importance of treating the troposphere and stratosphere as a whole system. In observational studies, Muench (1965) and Hirota and Sato (1969) showed the vertical propagation of planetary waves from the troposphere to the stratosphere by presenting time-height cross sections of wave amplitudes of wavenumbers 1 and 2. Many people observing the tropospheric and stratospheric circulations have noticed that some wave events in the troposphere can be traced into the stratosphere but some cannot. At present, however, there are few good presentations about the relation between the wave activity in the troposphere and in the stratosphere.

This paper will present the entire planetary wave activity in the troposphere and stratosphere by showing that there exist two different types of correspondence of wave activity between the troposphere and the stratosphere.

\section{Data and method of analysis}

The dataset used in this study is made up of the global tropospheric data for 1000 to $100 \mathrm{mb}$ and the global stratospheric data for 70 to $0.4 \mathrm{mb}$ produced operationally by the National Meteorological Center (NMC). (For details about the dataset, see Geller et al., 1983.) The following 18 pressure levels are available: $1000,850,700,500,400,300,250,200,150,100,70$, $50,30,10,5,2,1$ and $0.4 \mathrm{mb}$. First; we reduced the tropospheric data from the original twice-daily $2.5^{\circ}$ $\times 2.5^{\circ}$ longitude-latitude grids into daily $(1200 \mathrm{GMT})$ $5^{\circ} \times 5^{\circ}$ longitude-latitude grids. We also converted stratospheric data from polar stereographic grids $5 \times 5^{\circ}$ longitude-latitude grids. We then made a harmonic analysis along each latitude circle for wavenumbers 1 to 6 . Contributions of higher wavenumbers are quantitatively noticeable in the troposphere, but qualitatively insignificant for the present study. The analysis of the Northern Hemisphere was made during the four months from December 1981 to March 1982.

Observational results of the wave properties are presented principally by the quasi-geostrophic E-P flux and its divergence. (For a discussion, see Edmon et al., 1980; Dunkerton et al., 1981; Kanzawa, 1982.) We define the E-P flux $\mathbf{F}$ and wave driving $D_{F}$ by

where

$$
\mathbf{F}=(F(\theta), F(z))
$$

$$
\begin{aligned}
& F(\theta)=-\rho_{0}(z) a \cos \theta \overline{u^{\prime} v^{\prime}} \\
& F(z)=+\rho_{0}(z) a \cos \theta\left(\frac{f}{N^{2}}\right) \overline{v^{\prime} \Phi_{z}^{\prime}}
\end{aligned}
$$

$$
D_{F}=\frac{1}{\rho_{0}(z) a \cos \theta} \nabla \cdot \mathbf{F}
$$

where

$$
\nabla \cdot \mathbf{F}=\frac{1}{a \cos \theta} \frac{\partial(F(\theta) \cos \theta)}{\partial \theta}+\frac{\partial F(z)}{\partial z} .
$$

Then we can simply write the mean zonal momentum equation as

$$
\frac{\partial \bar{u}}{\partial t}-f \bar{v}^{*}=D_{F} .
$$

The notation is the same as that used by Shiotani and Hirota (1985). The wind field was estimated geostrophically from the geopotential height data. Hereafter, we refer to $F(\theta)$ and $(a \cos \theta)^{-1} \partial(F(\theta) \cos \theta) / \partial \theta$ as $F(y)$ and $\partial F(y) / \partial y$, respectively. Notice that the wave driving $D_{F}$ has the same dimensions as the acceleration of zonal flow and that it can be regarded as the zonal force per unit mass acting on the mean flow. Calculation of physical quantities is the same as in Shiotani and Hirota (1985) except that the buoyancy frequency $N$ is allowed to vary with latitude and height. We applied a 5-day running mean to most of the figures such as time-height and time-latitude cross sections for improving the graphical appearance.

\section{Results}

\section{a. General description}

As predicted by the theory of E-P flux diagnostics, the vertical component of the E-P flux, $F(z)$, is a measure of the vertical propagation of wave activity. Figure 1 shows a time-height cross section of $F(z)$ averaged over the latitude band of $40^{\circ}-70^{\circ} \mathrm{N}$ (not areaweighted). The validity for selecting this latitude band will be confirmed in subsection $3 \mathrm{~b}$. Major maximum points of the time series for each level, which were objectively determined from the low-pass ( $\geqslant 6.7$ days) filtered data, are marked by a "+" sign. (We used this data only to find maxima.) The contour interval is magnified five times above the $200 \mathrm{mb}$ level. The reader may consult Shiotani and Hirota (1985) for a detailed

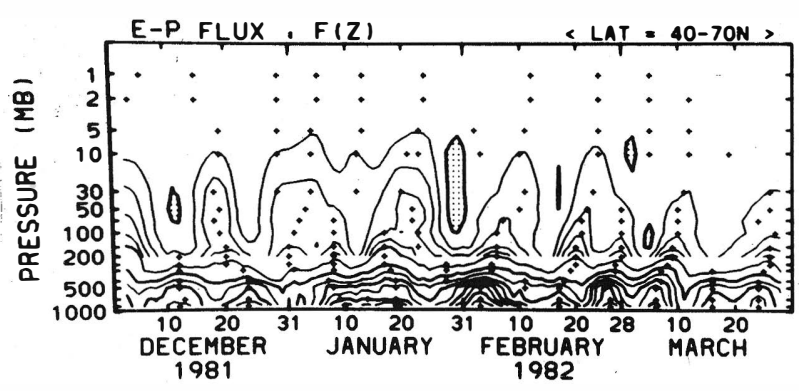

FIG. 1. Time-height cross section of the vertical component of the E-P flux, $F(z)$, averaged over $40^{\circ}$ to $70^{\circ} \mathrm{N}$. Contour interval is 2.5 $\times 10^{5} \mathrm{~kg} \mathrm{~s}^{-2}$; above $200 \mathrm{mb}$ it is magnified five times; negative values are shaded. Major maximum points are marked by a "+" (see text). 


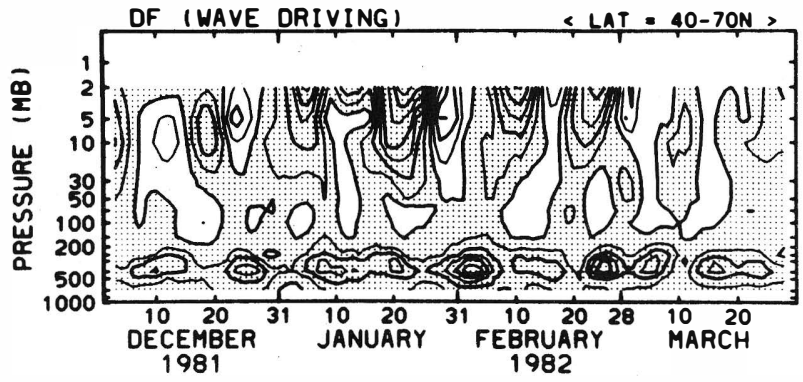

Fig. 2. Time-height cross section of wave driving $D_{F}$, averaged over $40^{\circ}$ to $70^{\circ} \mathrm{N}$. Contour interval is $4.0 \times 10^{-5} \mathrm{~m} \mathrm{~s}^{-2}$; negative values are shaded.

description of the dynamical aspect of the 1981/82 winter stratosphere in the Northern Hemisphere. We simply note for a reminder that a sudden warming occurred in late January $1982{ }^{1}$

At first sight, we can see that the magnitude of $F(z)$ varies with a period of 10-15 days in both the troposphere and the stratosphere; however, the correspondence of wave activity in the troposphere and stratosphere is different during the pre- and postwarming periods. (The tropopause lies around $300 \mathrm{mb}$ at this latitude band.) In December and early January the time variation of wave activity in the troposphere and stratosphere is out of phase; when the tropospheric wave activity is vigorous the stratospheric wave activity is quiet, and vice versa. In middle and late January the correspondence of wave activity in the troposphere and stratosphere is not clear. The major wave event in the stratosphere around 22 January, which was associated with the sudden warming, cannot be as simply traced back to the troposphere as wave events seen in February. After the sudden warming, in February and March, maximum wave activity can be traced from the troposphere to the stratosphere. The vertical propagation of planetary waves is obvious, as shown by Muench (1965) and Hirota and Sato (1969). However, the progress of wave activity is not regular but lagged around the tropopause level. This feature is similar to the result of Madden (1983), who showed the effect of the interference of traveling and stationary waves by using composited data to extract the 16-day waves.

As will be partly supported later (Figs. 5 and 15), the main contribution to the total wave activity comes from wavenumbers 1 to 3 in the troposphere during the Northern Hemisphere winter. We can reproduce almost the same figure as Fig. 1 with contributions from wavenumbers 1 to 3 . Thus, the features seen in Fig. 1 are due to the planetary-scale wave activity.

Regarding the negative correlation of wave activity in the troposphere and stratosphere, Koermer and Kao

\footnotetext{
${ }^{1}$ Critically speaking, this warming did not satisfy the WMO criterion of a major warming.
}

(1980) briefly reported a similar feature from the analysis of eddy kinetic energy. They compared the major and minor stratospheric warmings in the winters of $1976 / 77$ and $1975 / 76$, respectively, and noted that the time variation of the eddy kinetic energy in the troposphere and in the stratosphere is almost out of phase for the minor warming, but in phase for the major warming.

Figure 2 shows a time-height cross section of wave driving $D_{F}$. It is striking that a strong convergence zone exists around the $400 \mathrm{mb}$ level and that its magnitude varies with a time scale of 10-15 days. In their climatological studies of monthly or seasonal mean statistics using E-P flux diagnostics, the convergence zone in the upper troposphere is described by Edmon et al. (1980) and Geller et al. $(1983,1984)$ for the Northern Hemisphere, and by Hartmann et al. (1984) and Mechoso et al. (1985) for the Southern Hemisphere. We also observe the large temporal variation of $D_{F}$ in the upper stratosphere; however, we do not discuss it here (see Shiotani and Hirota, 1985, for a detailed discussion).

By comparing Fig. 1 to Fig. 2, we can see that the time variation of $D_{F}$ in the upper troposphere is closely related to the vertical component of the E-P flux, $F(z)$; they are in good negative correlation. (Notice $D_{F}<0$.) We will show later that $\left(\rho_{0}(z) a \cos \theta\right)^{-1} \partial F(z) / \partial z$ is the main contributor to the wave driving $D_{F}$ in the upper troposphere (see Fig. 4).

We will briefly look into the following evidence in the upper troposphere (Figs. 3-5) before moving into the subsection $3 \mathrm{~b}$. Figure 3 shows line plots of wave driving $D_{F}$ and $\partial \bar{u} / \partial t$ averaged over the $40^{\circ}-70^{\circ} \mathrm{N}$ latitude band and $250-500 \mathrm{mb}$ pressure level. We regard this region as representative of the upper troposphere. The difference of the mean value of $D_{F}$ and $\partial \bar{u} / \partial t$ is large; this means strong poleward residual circulation. However, $D_{F}$ and $\partial \bar{u} / \partial t$ are in reasonable correlation (correlation coefficient: $r=0.51$ ). In order to investigate the effect of wave driving on the zonal flow in the troposphere, correlation statistics of the relation between $D_{F}$ and $\partial \bar{u} / \partial t$ were performed by Hartmann et al. (1984) for the 1979 Southern Hemisphere winter and by

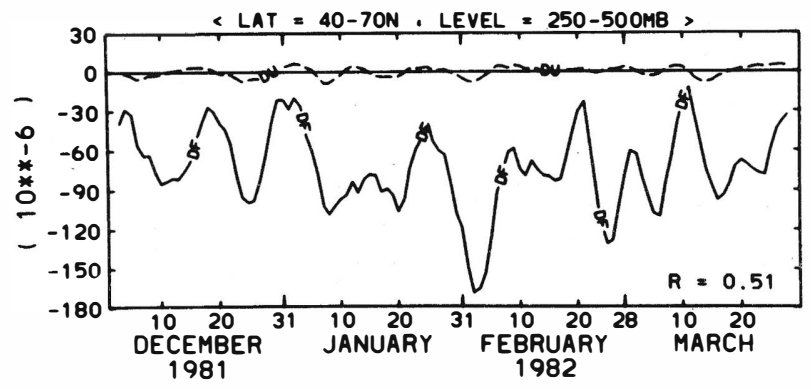

FIG. 3. Time series of $\partial \bar{u} / \partial t$ and wave driving $D_{F}$, averaged over $40^{\circ}$ to $70^{\circ} \mathrm{N}, 250-500 \mathrm{mb}$. Lines of $\partial \bar{u} / \partial t$ and $D_{F}$ are labeled "DU" and "DF," respectively. Units are $10^{-6} \mathrm{~m} \mathrm{~s}^{-2}$. 


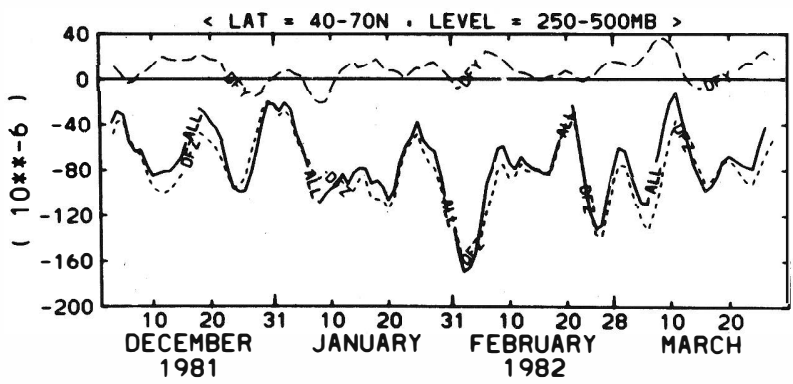

FIG. 4. Time series of $D_{F},\left(\rho_{0}(z) a \cos \theta\right)^{-1} \partial F(y) / \partial y$ and $\left(\rho_{0}(z) a\right.$ $\times \cos \theta)^{-1} \partial F(z) / \partial z$ averaged over $40^{\circ}$ to $70^{\circ} \mathrm{N}, 250-500 \mathrm{mb}$. Lines of $D_{F},\left(\rho_{0}(z) a \cos \theta\right)^{-1} \partial F(y) / \partial y$ and $\left(\rho_{0}(z) a \cos \theta\right)^{-1} \partial F(z) / \partial z$ are labeled "ALL," "DFY" and "DFZ," respectively. Units are $10^{-6} \mathrm{~m} \mathrm{~s}^{-2}$.

Baldwin et al. (1985) for the 1979 Northern Hemisphere winter. Using each latitude-height grid point, Hartmann et al. found a good correlation $(r>0.6)$ around the tropopause level. Baldwin et al., however, did not find as strong a relation $(r=0.34)$ for the upper troposphere, averaged over $30^{\circ}-60^{\circ} \mathrm{N}$ and $200-500$ $\mathrm{mb}$. Extending our statistics for each latitude-height grid point, we find a maximum $r>0.6$ in the upper troposphere. The reason for the low correlation coefficient of Baldwin et al. (1985) may be due to an inappropriate selection of the representative region.

Figures 1 and 2 suggested that the vertical derivative of $F(z)$ is important to the wave driving $D_{F}$ in the upper troposphere. Figure 4 shows line plots of the contribution of $\left(\rho_{0}(z) a \cos \theta\right)^{-1} \partial F(y) / \partial y$ and $\left(\rho_{0}(z) a \cos \theta\right)^{-1}$ $\times \partial F(z) / \partial z$. Around the high-latitude upper troposphere, most of the contribution to $D_{F}$ comes from the vertical derivative of $F(z)$.

Figure 5 shows line plots of the total (wavenumber 1 to 6) $F(z)$ and the contribution from wavenumber $i$ $(i=1$ to 3 ) for the same region as Figs. 3 and 4; the contribution from wavenumber 4 to 6 is small during th. ; period. Most of the total variation is explained by the wavenumber 2 (and 3) contribution. (Some statistical comparisons with the Southern Hemisphere will be shown in section 4.) The tendency of the wavenumber contributions of wave driving $D_{F}$ is similar to that of $F(z)$, as suggested by Fig. 4 . Because the wavenumber 2 activity is still the main contributor to the total $F(z)$ in the lower stratosphere (not shown), the out-of-phase relationship seen in Fig. 1 does not appear to be due to the selective transmission of planetary-scale waves.

On the other hand, Shiotani and Hirota (1985) pointed out that most of the wave activity in the upper stratosphere for the 1981/82 winter in the Northern Hemisphere is accounted for by wavenumber 1 planetary waves. Careful tracing of each wave event shows that wavenumber 2 activity is sometimes deformed into wavenumber 1 activity with increasing altitude. This strongly suggests a wave-wave interaction process (Smith 1983; Smith et al., 1984); however, we will not discuss this possibility here. When we look at the time variation of each wavenumber in Fig. 5, the rhythm of total $F(z)$ with a period of 10-15 days is obscured. Because of these reasons, we show total wave activity, not each wavenumber activity.

\section{b. Features around the tropopause level}

In this subsection we present the latitudinal variation of eddy properties $[F(z)$ and $F(y)]$ and zonal mean field $(\bar{u}$ and refractive index) around the tropopause level from time-latitude cross sections. We shall pay particular attention to the dynamical difference between the pre- and postwarming periods.

Figures $6 \mathrm{a}, \mathrm{b}$ and $\mathrm{c}$ show time-latitude cross sections of $F(z)$ for 500,300 and $100 \mathrm{mb}$, respectively. From these figures we reconfirm the correspondence of $F(z)$ between the troposphere and the stratosphere in detail. Throughout the whole period observed, i.e., from December 1981 to March 1982, the time variation of $F(z)$ with a time scale of $10-15$ days is obvious for the three levels. At the $500 \mathrm{mb}$ level (Fig. 6a) there are two major wave events in December (around 12 and 26 December). Then, at the $300 \mathrm{mb}$ level (Fig. 6b), one of the two events (around 12 December) diminishes, the other (around 26 December) disappears, and a new major wave event appears (around 20 December). Finally, at the $100 \mathrm{mb}$ level (Fig. 6c), two major wave events around 20 December and early January are apparent. Thus the time variation of wave activity in the troposphere (Fig. 6a) and the lower stratosphere (Fig. 6c) looks out of phase, as seen in Fig. 1. On the other hand, in the postwarming period, most of the major wave events can be traced through $500 \rightarrow 300 \rightarrow 100 \mathrm{mb}$ with a time lag.

Another interesting feature is latitudinal variation of the maximum $F(z)$. At the $500 \mathrm{mb}$ level (Fig. 6a), the maximum $F(z)$ lies around $50^{\circ} \mathrm{N}$ and the magnitude of $F(z)$ seems somewhat larger in the postwarming period than in the prewarming period. At the $300 \mathrm{mb}$ level (Fig. 6b), however, it shifts to around $40^{\circ}-45^{\circ} \mathrm{N}$ in the prewarming period, while it still lies around $50^{\circ} \mathrm{N}$ in the postwarming period. At the $100 \mathrm{mb}$ level (Fig. $6 \mathrm{c})$, the maximum $F(z)$ shifts poleward, around $60^{\circ} \mathrm{N}$.

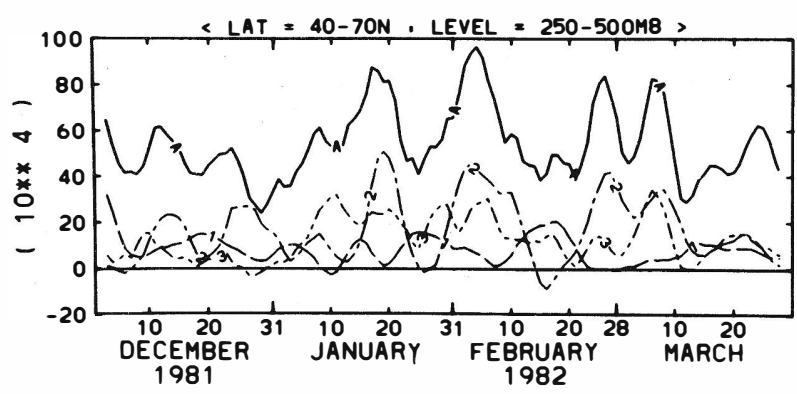

FIG. 5. Time series of $F(z)$ and the contribution from wavenumber 1 to 3 , averaged over $40^{\circ}$ to $70^{\circ} \mathrm{N}, 250-500 \mathrm{mb}$. The thick solid line labeled "A" represents total (wavenumber 1 to 6) $F(z)$. The thin dotted lines represent the contribution from wavenumber $i(i=1$ to 3$)$. Units are $10^{4} \mathrm{~kg} \mathrm{~s}^{-2}$. 
(a)

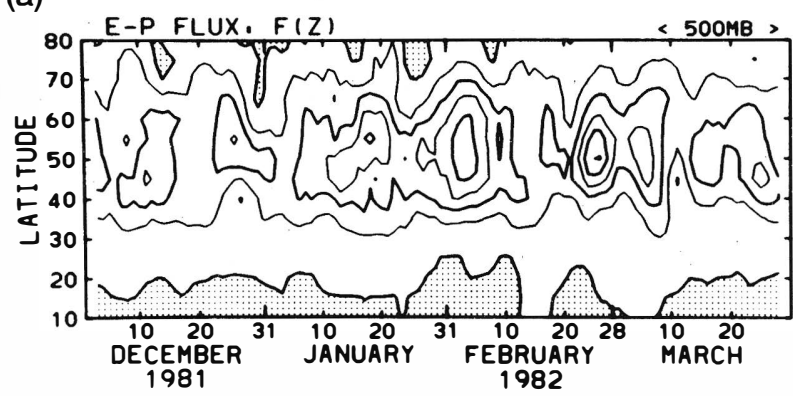

(c)

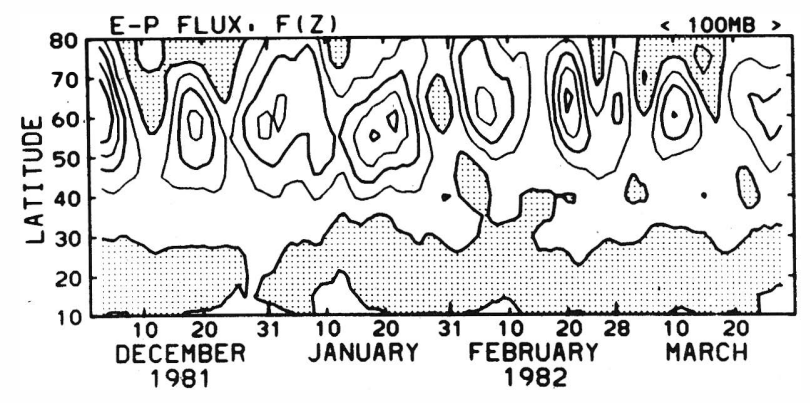

Figure 7 shows a time-latitude cross section of the horizontal component of the E-P flux, $F(y)$, at the 300 mb level; the features of $F(y)$ are almost the same around the tropopause levels. For most of the period we see a positive region at high latitudes, a negative region at middle latitudes, and a positive region again at low latitudes. These latitudinal variations of $F(y)$ should contribute to wave driving $D_{F}$ from $\partial F(y) / \partial y$. Figure 4 showed, however, that the contribution of $\left(\rho_{0}(z) a \cos \theta\right)^{-1} \partial F(y) / \partial y$ is smaller than that of $\left(\rho_{0}(z) a\right.$ $\times \cos \theta)^{-1} \partial F(z) / \partial z$, and that $\left(\rho_{0}(z) a \cos \theta\right)^{-1} \partial F(y) / \partial y$ is generally positive at the $40^{\circ}-70^{\circ} \mathrm{N}$ latitude band, as expected from Fig. 7. Compared with the figure of $F(z)$ at the same level (Fig. 6b), times of maximum $F(z)$ and minimum (negative maximum) $F(y)$ occur almost simultaneously in the prewarming period, while minima of $F(y)$ are delayed a few days in the postwarming period. In their model calculation of the life cycle of baroclinic waves, Edmon et al. (1980) reported a similar feature as observed in the postwarming period of my

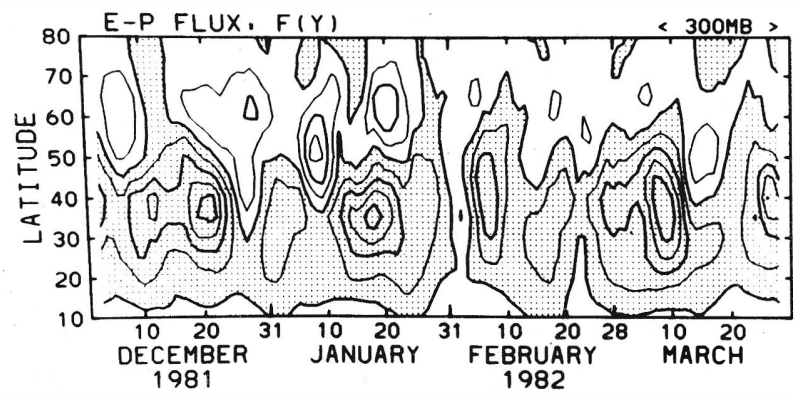

FIG. 7. Time-latitude cross section of $F(y)$ at $300 \mathrm{mb}$. Contour interval is $4.0 \times 10^{7} \mathrm{~kg} \mathrm{~s}^{-2}$; negative values are shaded. (b)

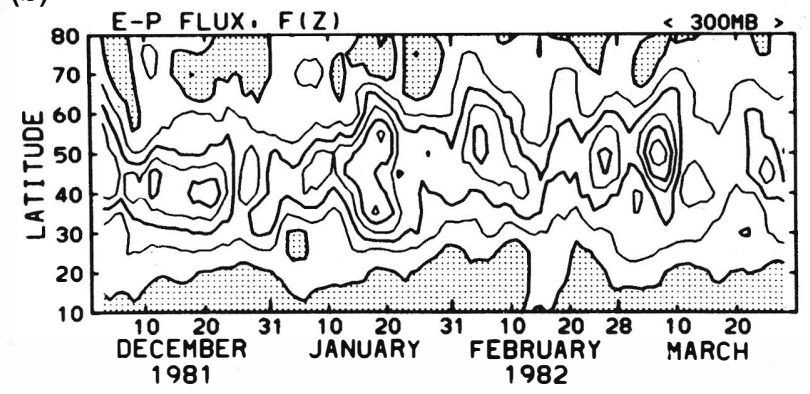

FIG. 6. Time-latitude cross sections of $F(z)$ at (a) 500, (b) 300 and (c) $100 \mathrm{mb}$. Contour intervals are $5.0 \times 10^{5}, 2.0 \times 10^{5}$ and 6.0 $\times 10^{4} \mathrm{~kg} \mathrm{~s}^{-2}$, respectively; negative values are shaded.

study. The magnitude of $F(y)$, particularly positive $F(y)$ at high latitudes, is larger in the prewarming period than in the postwarming period.

We have noted many differences of eddy properties in the pre- and postwarming periods. Now, we will show zonal mean field such as mean zonal geostrophic wind and refractive index. Following Kanzawa (1982), we define the refractive index $Q_{k}$ for a stationary linear wave by

$$
Q_{k}=\frac{\bar{q}_{y}}{\bar{u}}-\frac{k^{2}}{(a \cos \theta)^{2}}-\frac{f^{2}}{4 N^{2} H^{2}}
$$

where

$$
\begin{aligned}
\bar{q}_{y}=\frac{2 \Omega \cos \theta}{a}-\frac{\partial}{a \partial \theta}\left(\frac{1}{\cos \theta} \frac{\partial}{a \partial \theta} \bar{u} \cos \theta\right) & \\
& -\frac{\partial}{\rho_{0} \partial z}\left[\rho_{0}\left(\frac{f}{N}\right)^{2} \frac{\partial \bar{u}}{\partial z}\right] .
\end{aligned}
$$

Here $k$ is the zonal wavenumber. In the real atmosphere, planetary waves are generally neither stationary nor linear. Therefore, we use the refractive index defined by (3.1) just as a rough indication of the mean state and we treat $N$ as a constant $\left(=2.0 \times 10^{-2} \mathrm{~s}^{-1}\right)$ for simplicity. Because the first term on the right-hand side of (3.1) is dominant for the earth's atmosphere, we will show $Q_{0}$ as the refractive index in this study.

Figure 8 shows the mean zonal geostrophic wind at the $400 \mathrm{mb}$ level. The tropospheric jet is located around $35^{\circ} \mathrm{N}$ in December and around $30^{\circ} \mathrm{N}$ in February. In connection with this movement, the meridional gradient of the zonal wind at high latitudes is steeper in December than in February. The refractive index in Fig. 9 clearly shows these differences; low value regions 


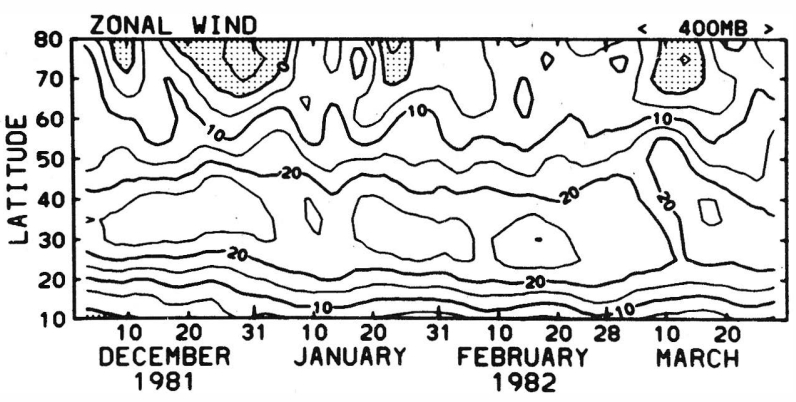

FIG. 8. Time-latitude cross section of mean zonal geostrophic wind at $400 \mathrm{mb}$. Contour interval is $5 \mathrm{~m} \mathrm{~s}^{-1}$; negative values are shaded.

(hatched under 60) around $50^{\circ} \mathrm{N}$ in December move equatorward to around $30^{\circ}-40^{\circ} \mathrm{N}$ in early January and remain there until the end of March. In middle March, the tropospheric jet shifts poleward and the latitudinal gradient of the zonal wind at high latitudes becomes steeper again for about 10 days. It is interesting to find in Fig. 1 that, around 16 March, the tropospheric wave activity is vigorous while the stratospheric wave activity is quiet, which is the same relation as typically seen in the prewarming period.

According to the ray theory (cf. Karoly and Hoskins, 1982), wave activity is refracted toward larger values of the refractive index. If we apply this principle in order to understand the dynamical difference between the pre- and postwarming periods, we can suppose that in the prewarming period waves are refracted more equatorward because of the positive slope of the refractive index at middle latitudes and that in the postwarming period waves are guided more upward into the stratosphere because of the minimum $Q_{0}$ around $30^{\circ}-40^{\circ} \mathrm{N}$. This explanation is consistent with Fig. $6 \mathrm{~b}$, which shows more equatorward position of maximum $F(z)$ at the $300 \mathrm{mb}$ level in the prewarming period than in the postwarming period. Thus, the two types of correspondence of the wave activity in the troposphere and in the stratosphere are closely related to the zonal wind profile.

\section{c. Comparison between the pre-and postwarming pe- riods}

Subsection $3 b$ has shown many dynamical differences between the pre- and postwarming periods for the 1981/82 winter in the Northern Hemisphere. To summarize these features we chose two typical periods, 30 days of the prewarming period (beginning at 4 December) and of the postwarming period (beginning at 1 February), and made period-mean latitude-height cross sections for the two periods. Hereafter, we call the selected prewarming period "period 1" and the selected postwarming period "period 2."

In the cross sections of the mean zonal geostrophic wind (Figs. 10a, b), we see the following differences between periods 1 and 2. The position of the tropospheric jet is more poleward in period $1\left(35^{\circ} \mathrm{N}\right)$ than in period $2\left(25^{\circ}-30^{\circ} \mathrm{N}\right)$. The latitudinal gradient of the zonal wind at high latitudes (around $60^{\circ}-80^{\circ} \mathrm{N}$ ) in the troposphere and lower stratosphere is steeper in period 1 than in period 2. Referring to a climatological study of monthly mean cross sections for four years by Geller et al. (1984), we see that the latitudinal gradient of the zonal wind at high latitudes of the troposphere and lower stratosphere tends to become more gradual from December to February for each of the four years studied. The stratospheric westerlies in period 2 are weaker in the midlatitude upper stratosphere and slightly stronger in the high-latitude stratosphere.

Figures $11 \mathrm{a}, \mathrm{b}$ show the latitude-height cross sections of the refractive index $Q_{0}$ calculated from period-mean wind fields (Figs. 10a, b). The difference in the troposphere in Fig. 11 is not as noticeable as in Fig. 9; however, these two cross sections look different in the stratosphere. A low value region in the midlatitude lower stratosphere is more prominent in period 2 than in period 1 . Another low value region in the high-latitude upper stratosphcre is pushed more downward and equatorward in period 1 than in period 2 . From these features, we expect that the vertical propagation of planetary waves in the stratosphere would be more effective in period 2 than in period 1 .

Figures 12a, b show the latitude-height cross sections of the E-P vectors and wave driving $D_{F}$. They were calculated from a 30-day average of daily values, not from a 30-day mean field. In plotting the E-P flux in the vertical cross section we follow the graphical convention as described by Baldwin et al. (1985); we have multiplied $\mathbf{F}$ by the factor $\exp (z / H)$. In the troposphere and lower stratosphere the E-P vectors branch off equatorward and poleward around the tropopause level in period 1, while they regularly point upward with a slight equatorward drift in period 2 . In the stratosphere the E-P vectors at high latitudes point more equatorward in period 1 than in period 2. These features of the wave refraction in the troposphere and stratosphere are in broad agreement with Figs. 9 and 11. The mag-

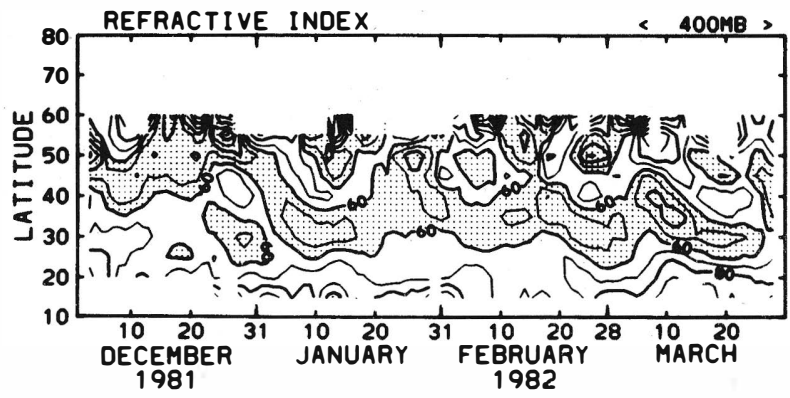

FIG. 9. Time-latitude cross section of the refractive index $Q$ at $400 \mathrm{mb}$. Values are multiplied by $a^{2}$ ( $a$ : radius of the earth). Contour interval is 10 ; regions under 60 are shaded. Latitude band of $15^{\circ}$ to $60^{\circ} \mathrm{N}$ and value range of 0 to 100 are shown. 
(a)

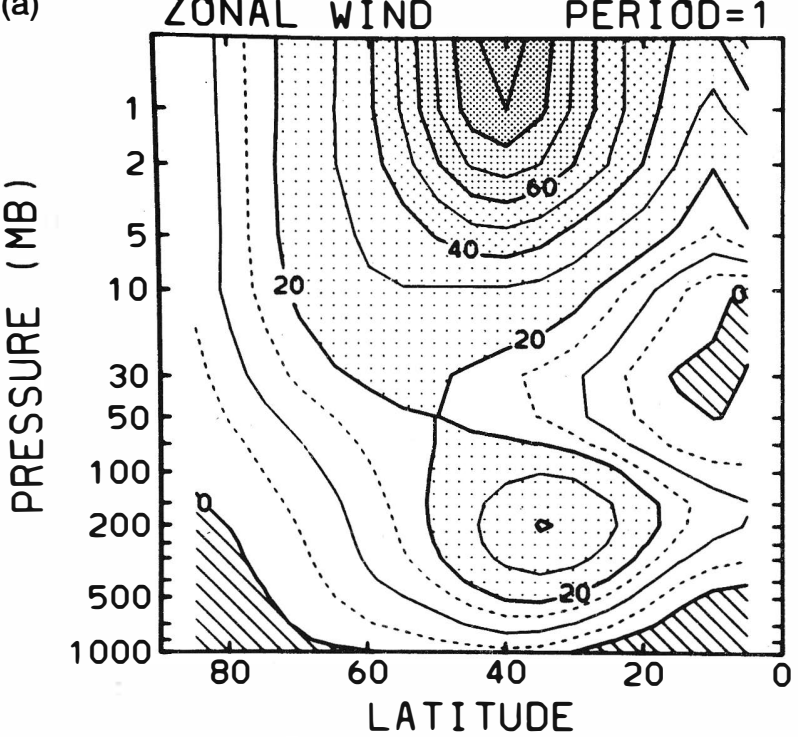

(b)

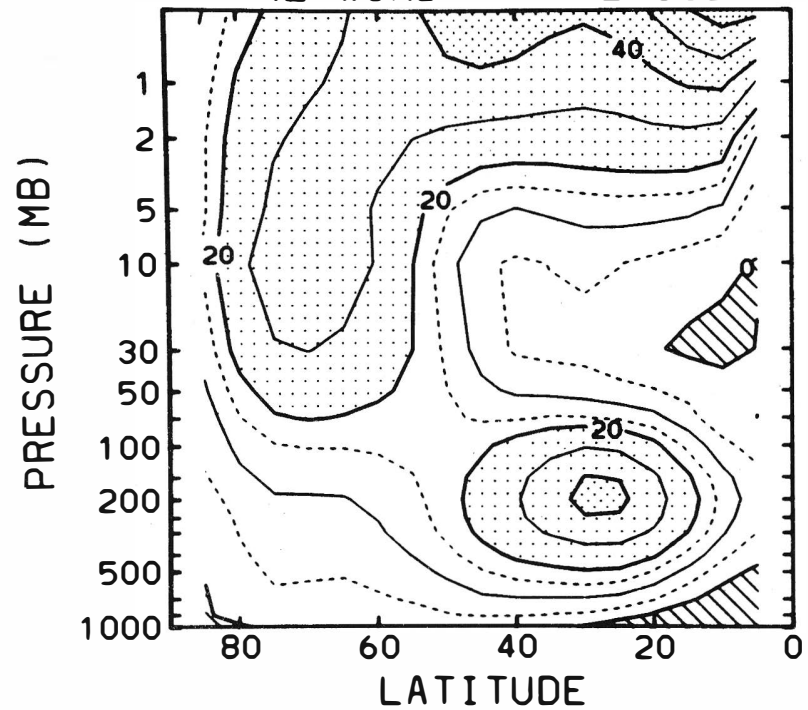

FIG. 10. Latitude-height cross sections of mean zonal geostrophic wind for (a) period 1 and (b) period 2 (see text for terminology). Solid contour interval is $10 \mathrm{~m} \mathrm{~s}^{-1}$; dashed lines are drawn for 5 and $15 \mathrm{~m} \mathrm{~s}^{-1}$.

nitude of $F(z)$ in the lower troposphere is larger in period 2 than in period 1 , and the magnitude of $F(y)$ around the tropopause level, both positive and negative, is larger in period 1 than period 2. As for the wave driving $D_{F}$, a strong convergence zone exists at high latitudes at the $400 \mathrm{mb}$ level. In period 1 another convergence zone exists around $35^{\circ} \mathrm{N}$ and the $250 \mathrm{mb}$ level; this may tend to maintain the weaker tropospheric jet in period 1 (see Fig. 10). In period 1, there is a strong divergence zone in the polar middle strato- sphere; this suggests the source of wave activity in the stratosphere. We can summarize these features of Figs. 10-12 as showing that the atmosphere in the troposphere and lower stratosphere is more barotropic in period 1 and more baroclinic in period 2 .

Recently, using a stratospheric general circulation model, Boville (1986) made a comparison of the tropospheric and stratospheric circulations before and after a major warming. By showing figures of zonal wind, refractive index and E-P vectors, he suggested that the (a)

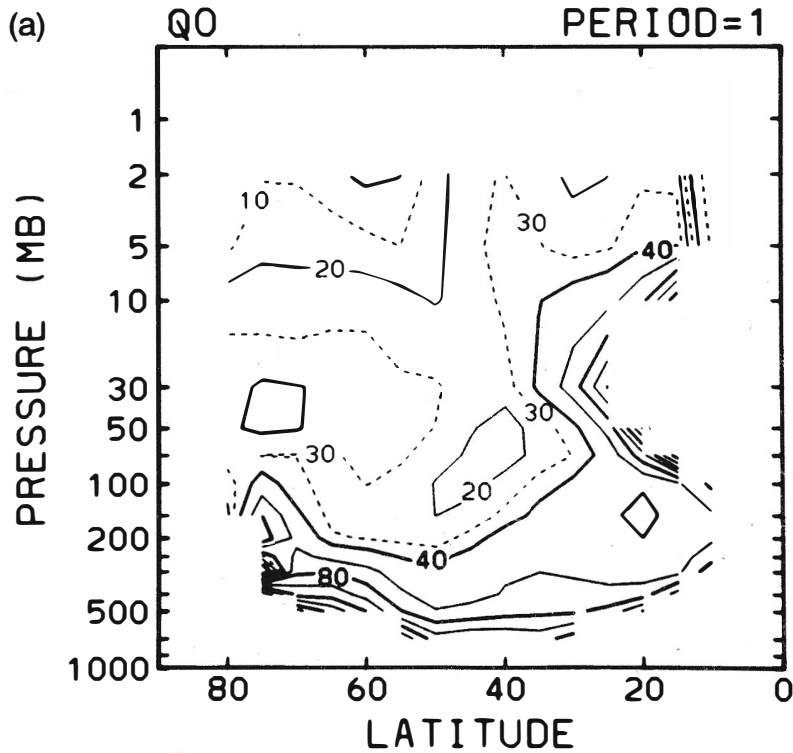

(b)

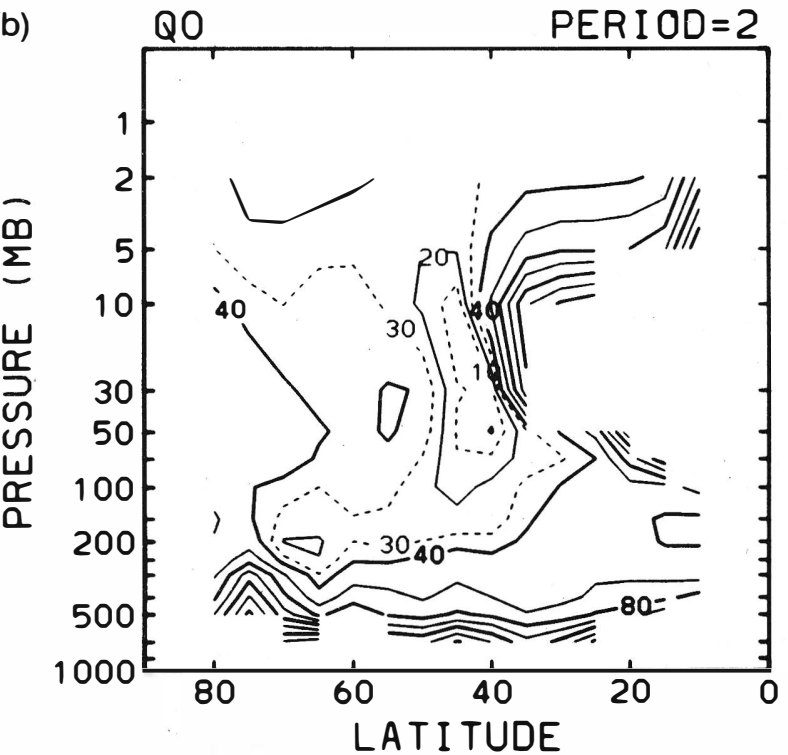

FIG. 11. As in Fig. 10 but for the refractive index $Q_{0}$. Solid contour interval is 20; dashed lines are drawn for 10 and 30. Value range of -200 to 200 is shown. 
(a)

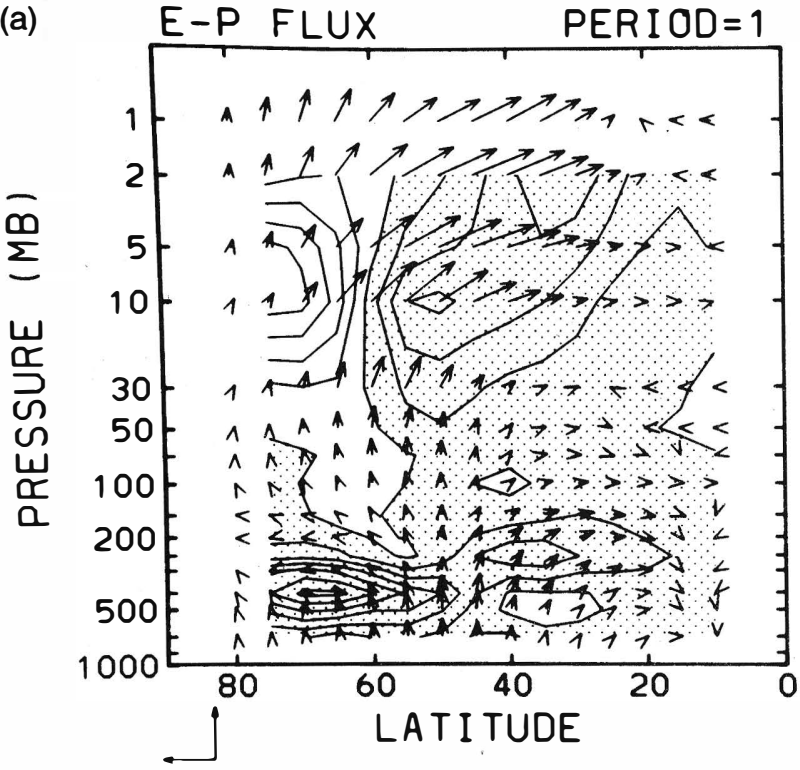

(b)

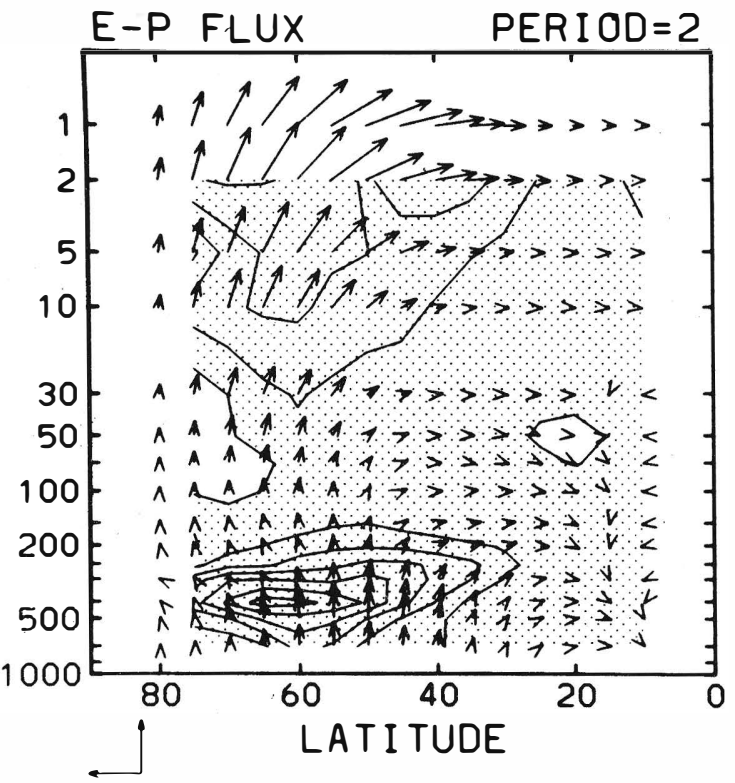

FIG. 12. As in Fig. 10 but for the E-P flux and wave driving $D_{F}$. Contour interval of $D_{F}$ is $2.5 \times 10^{-5} \mathrm{~m} \mathrm{~s}^{-2}$; negative values are shaded. Reference arrow shows $1.0 \times 10^{9} \mathrm{~kg} \mathrm{~s}^{-2}$ for horizontal direction and $1.0 \times 10^{9} / c(c=182) \mathrm{kg} \mathrm{s}^{-2}$ for vertical direction. (See text for the scaling.)

stronger stratospheric winds in the prewarming period tend to inhibit the vertical propagation of wave activity into the polar stratosphere, while the weaker stratospheric winds in the postwarming period provide more effective vertical propagation of wave activity into the polar stratosphere. There are some differences between our results and Boville's; for example, our zonal winds at high latitudes are slightly weaker in the prewarming period than in the postwarming period. However, our results of Figs. 10-12 are consistent with those of Boville; he showed that the vertical propagation of wave activity is more effective in the postwarming period than in the prewarming period.

\section{Concluding remarks}

This study has shown that there are typically two types of correspondence between wave activity in the troposphere and stratosphere for the 1981/82 winter in the Northern Hemisphere. One is characterized by an out-of-phase relationship between wave activity in the troposphere and stratosphere, and the other by upward propagation from the troposphere to the stratosphere. These two types of correspondence occur with durations of more than one month before and after the sudden warming, respectively. The dynamical aspect of the two periods is summarized in subsection $3 \mathrm{c}$; briefly, the atmosphere in the troposphere and lower stratosphere is more barotropic in the prewarming period and more baroclinic in the postwarming period for the 1981/82 Northern Hemisphere winter. Moreover, it has been shown that there exists a strong convergence zone of the E-P flux in the upper troposphere and that the magnitude of it varies with a typical time scale of 10-15 days. This is closely related to the time variation of wave activity in the troposphere and stratosphere.

Some readers may be curious about whether these atmospheric features can be seen for other winters or for the Southern Hemisphere. Data covering two years for both hemispheres is available to our laboratory (Kyoto). Therefore, we will briefly describe another winter of the Northern and Southern hemispheres. In the 1982/83 winter in the Northern Hemisphere, the two types of correspondence can sometimes be seen; however, most of the events are sporadic and not continuous. Also, there is no scenario of the pre- and postwarming period. For the 1981 Southern Hemisphere winter, cross sections similar to Figs. 1 and 2 are shown in Figs. 13 and 14, respectively. From late August to September the vertical propagation of planetary waves is clearly suggested in the troposphere and lower stratosphere. In late July and October, wave activity

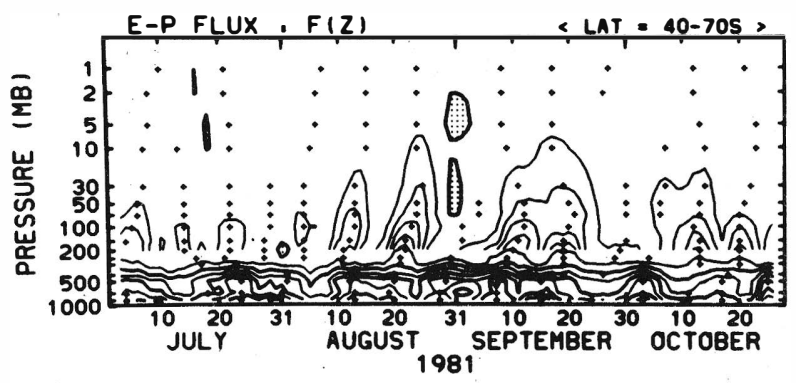

FIG. 13. As in Fig. 1 but for the 1981 Southern Hemisphere winter. Contour interval is $3.0 \times 10^{5} \mathrm{~kg} \mathrm{~s}^{-2}$. 
between the troposphere and stratosphere looks out of phase. As for wave driving $D_{F}$, it is clear that there exists a strong convergence zone in the upper troposphere and that the magnitude of it varies with a time scale of 15-20 days. Thus, the features seen in Figs. 1 and 2 for the Northern Hemisphere are present in the Southern Hemisphere as well.

However, there is an interesting difference in the wavenumber contribution to $F(z)$ between the Northern and Southern hemispheres. Figure 15 shows 120 day mean $F(z)$ of each wavenumber (from 1 to 6) averaged over $250-500 \mathrm{mb}$ and $40^{\circ}-70^{\circ} \mathrm{N}$, S. The difference of contribution from wavenumber 1 to 6 is apparent between the Northern and Southern hemispheres. In the Northern Hemisphere most of the contribution comes from wavenumber 2 (and 3), while in the Southern Hemisphere it comes from wavenumber 3 to 5 (or 6). In the Northern Hemisphere, because of the prominent land-sea contrast, the planetary-scale waves generated in the troposphere by orographic forcing and diabatic heating are the main contributors to the total wave activity of $F(z)$. On the other hand, in the Southern Hemisphere, where the land-sea contrast is not as prominent, baroclinic disturbances with synoptic scale can account for the total wave activity of $F(z)$. Although the main contribution to $F(z)$ comes from different horizontal scale eddies between the Northern and Southern hemispheres, it is interesting to see in Figs. 1, 2 and 13,14 that the time variations of total wave activity in the troposphere of both hemispheres have similar periodicities of about two weeks.

Regarding the physical mechanism of the vertically propagating type, interference of stationary and traveling waves is a possible idea. Recently, Madden (1983), Smith (1985) and Hirooka (1986) have shown evidence of interference between traveling and stationary planetary waves in the stratosphere. This mechanism is helpful for understanding the vertical propagation type; for example, the mechanistic model study of Hirota (1971) simply showed that both the time-dependent upward propagation of planetary waves and the interference of stationary and traveling waves originally have the same dynamical aspect (see Figs. 6 and 8 of Hirota, 1971.) Hirota (1971) postulated a periodic forcing in

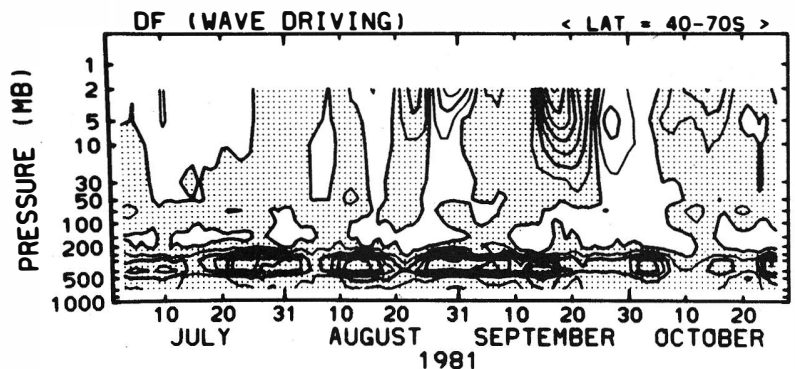

FIG. 14. As in Fig. 2 but for the 1981 Southern Hemisphere winter. Contour interval is $2.0 \times 10^{-5} \mathrm{~m} \mathrm{~s}^{-2}$.

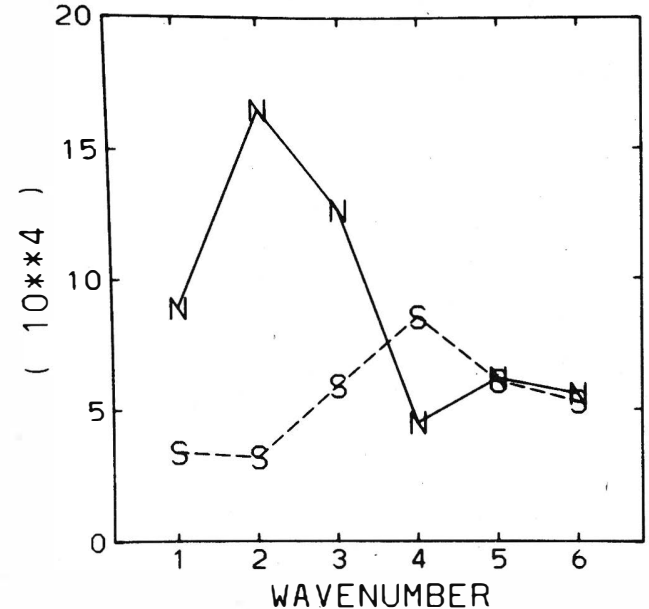

FIG. 15. 120-day mean $F(z)$ of each wavenumber (from 1 to 6 ) averaged over $250-500 \mathrm{mb}$ and $40^{\circ}-70^{\circ}$ latitude for the Northern and Southern Hemispheres. (See Figs. 1 and 15 for the period of the 120-day mean.) "N" and "S" indicate Northern Hemisphere and Southern Hemisphere, respectively. Units are $10^{4} \mathrm{~kg} \mathrm{~s}^{-2}$.

the lower atmosphere a priori. Thus he did not give any answer to the generation of traveling waves in the atmosphere.

The physical interpretation of the out-of-phase relationship of wave activity in the troposphere and stratosphere is not yet apparent. As suggested by the present study and by Boville (1986), the zonal wind structure in the prewarming period tends to suppress the vertical propagation of wave activity in the stratosphere. However, there still remains the question of why the stratospheric wave activity becomes vigorous when the tropospheric wave activity is quiet. It would be interesting to reproduce this feature by using a numerical model.

The results of Boville (1986) are also suggestive concerning the question of what determines the choice of these two types of correspondence. In a general circulation model using fixed external forcing, Boville found two different mean states for the winter stratosphere before and after a sudden warming, similar to this study. This means that the two states come from the internal process of wave-mean flow interactions. Recently, Yoden et al. (1986) found two typical circulation patterns in the 1983 Southern Hemisphere winter; one is a single-jet regime and the other has a double jet. Yoden et al. observed the transition from one to the other regime several times and proposed that this low-frequency variation can be understood as almost intransitive with multiple weather regimes. The annual variation is larger in the Northern Hemisphere than in the Southern Hemisphere; however, the results presented here suggest that there exist multiple states of the general circulation.

The main thrust of this paper is to show the importance of treating the troposphere and stratosphere as a 
whole, in order to understand real atmospheric behavior.

Acknowledgments. I wish to thank Prof. I. Hirota of the Geophysical Institute of Kyoto University for his continuing guidance and valuable discussions throughout this work. I am also grateful Dr. J. C. Gille for his critical reading of the manuscript. Thanks are also due to Drs. B. A. Boville, W. J. Randel, S. Yoden and two anonymous reviewers for their helpful comments on the manuscript. This work was supported in part by NASA under Interagency Agreement W15439.

\section{REFERENCES}

Baldwin, M. P., H. J. Edmon, and J. R. Holton, 1985: A diagnostic study of eddy-mean flow interaction during FGGE SOP-1. $J$. Atmos. Sci., 42, 1838-1845.

Boville, B. A., 1984: The influence of the polar night jet on the tropospheric circulation in a GCM. J. Atmos. Sci., 41, 1132-1142.

- 1986: Wave-mean flow interactions in a general circulation model of the troposphere and stratosphere. J. Atmos. Sci., 43, 1711-1725.

Dunkerton, T., C.-P. Hsu and M. E. McIntyre, 1981: Some Eulerian and Lagrangian diagnostics for a model stratospheric warming. J. Atmos. Sci., 38, 819-843.

Edmon, H. J., B. J. Hoskins and M. E. McIntyre, 1980: EliassenPalm cross sections for the troposphere. J. Atmos. Sci., 37, 26002616. (See also Corrigendum, J. Atmos. Sci., 38, 1115, especially penultimate item.)

Geller, M. A., M.-F. Wu and M. E. Gelman, 1983: Tropospherestratosphere (surface-55 km) monthly winter general circulation statistics for the Northern Hemisphere-four year averages. $J$. Atmos. Sci., 40, 1334-1352.

,-- and -1984 : Troposphere-stratosphere (surface-55 $\mathrm{km}$ ) monthly winter general circulation statistics for the Northern Hemisphere-interannual variations. J. Atmos. Sci., 41, 17261744.

Gille, J. C., and L. V. Lyjak, 1984: An overview of wave-mean flow interactions during the winter of 1978-79 derived from LIMS observations. Dynamics of the Middle Atmosphere. J. R. Holton and T. Matsuno, Eds., Terra Scientific, 543 pp.

Hartmann, D. L., C. R. Mechoso and K. Yama zaki, 1984: Observations of wave-mean flow interaction in the Southern Hemisphere. J. Atmos. Sci., 41, 351-362.

Hirooka, T., 1986: Influence of normal-mode Rossby waves on the mean field: Interference with quasi-stationary waves. J. Atmos. Sci., 43, 2088-2097.

Hirota, I., 1971: Excitation of planetary Rossby waves in the winter stratosphere by periodic forcing. J. Meteor. Soc. Japan, 49, 439449.

- and Y. Sato, 1969: Periodic variation of the winter stratospheric circulation and intermittent vertical propagation of planetary waves. J. Meteor. Soc. Japan, 47, 390-402.

Kanzawa, H., 1982: Eliassen-Palm flux diagnostics and the effect of the mean wind on planetary wave propagation for an observed sudden stratospheric warming. J. Meteor. Soc. Japan, 60, 10631073.

Karoly, D. J., and B. J. Hoskins, 1982: Three dimensional propagation of planetary waves. J. Meteor. Soc. Japan, 60, 109-123.

Koermer, J. P., and S. K. Kao, 1980: Major and minor stratospheric warmings and their interaction on the troposphere. Pure Appl. Geophys., 118, 428-451.

McIntyre, M. E., 1982: How well do we understand the dynamics of stratospheric warmings? J. Meteor. Soc. Japan, 60, 37-65.

Madden, R. A., 1983: The effect of the interference of traveling and stationary waves on time variations of the large-scale circulation. J. Atmos. Sci., 40, 1110-1125.

Matsuno, T., 1971: A dynamical model of the stratospheric sudden warming. J. Atmos. Sci., 28, 1479-1494.

Mechoso, C. R., D. L. Hartmann and J. D. Farrara, 1985: Climatology and interannual variability of wave-mean flow interaction in the Southern Hemisphere. J. Atmos. Sci., 42, 2189-2206.

Muench, H. S., 1965: On the dynamics of wintertime stratospheric circulation. J. Atmos. Sci., 22, 349-360.

O'Neill, A., and C. E. Youngblut, 1982: Stratospheric warmings diagnosed using the trans formed Eulerian-mean equations and the effect of the mean state on wave propagation. J. Atmos. Sci., 39, 1370-1386.

Palmer, T. N., 1981: Diagnostic study of a wavenumber-2 stratospheric sudden warming in a transformed Eulerian-mean formalism. J. Atmos. Sci., 38, 844-855.

Shiotani, M., and I. Hirota, 1985: Planetary wave-mean flow interaction in the stratosphere: A comparison between Northern and Southern hemispheres. Quart. J. Roy. Meteor. Soc., 111, 309334.

Smith, A. K., 1983: Observation of wave-wave interactions in the stratosphere. J. Atmos. Sci., 40, 2484-2496.

- , 1985: Wave transience and wave-mean flow interaction caused by the interference of stationary and traveling waves. J. Atmos. Sci., 42, 529-535.

- J. C. Gille and L. V. Lyjak, 1984: Wave-wave interactions in the stratosphere: Observations during quiet and active wintertime periods. J. Atmos. Sci., 41, 363-373.

Tung, K. K., and R. S. Lind zen, 1979: A theory of stationary long waves. Part II: resonant Rossby waves in the presence of realistic vertical shears. Mon. Wea. Rev., 107, 735-750.

Wallace, J. M., and M. L. Blackmon, 1983: Observations of lowfrequency atmospheric variability. Large-Scale Dynamical Processes in the Atmosphere. B. J. Hoskins and R. P. Pearce, Eds., Academic Press, 397 pp.

Yoden, S., M. Shiotani and I. Hirota, 1986: Multiple weather regimes in the Southern Hemisphere. J. Meteor. Soc. Japan. 